\title{
Yellowish flecks in Leber's congenital amaurosis
}

\author{
E. CHEW,' A. DEUTMAN, ${ }^{2}$ A. PINCKERS,,$^{2}$ AND A. AAN DE KERK ${ }^{2}$ \\ From the 'Hospital for Sick Children, Toronto, Canada, and the 'Institute of Ophthalmology, \\ University of Nijmegen, Nijmegen, The Netherlands
}

SUMMARY The fundus abnormalities of Leber's congenital amaurosis are extremely variable, from normal to salt-and-pepper changes to typical retinitis pigmentosa. A less commonly seen appearance is that of multiple, irregular shaped, yellowish white flecks deep in the midperipheral retina in a periarteriolar distribution. The nasal fundus as well as the posterior pole are spared. Such a case is presented along with a four-year follow-up together with the fluorescein angiographic findings. The flecks appear to be specific for this entity.

In 1896 Leber originally described a syndrome of congenital blindness with nystagmus, poor pupillary response, and funduscopic findings of tapetoretinal degeneration.' In 1954 Franceschetti and Dieterle ${ }^{2}$ emphasised the importance of a markedly abnormal or extinct electroretinogram (ERG) in the diagnosis of the syndrome complex now known as Leber's congenital amaurosis. Other findings of this autosomal recessive inherited disease include photophobia, digito-ocular sign, and subsequent sunken eyeballs. There may be associated ocular and systemic abnormalities such as keratoconus, keratoglobus, cataract, strabismus, mental retardation, deafness, renal dysgenesis, and neurological deficits. The modern nomenclature of Leber's congenital amaurosis has been challenged by some i: estigators as to its representation of the views of the original author.

The fundus changes in this syndrome are extremely variable ${ }^{+}$from normal ${ }^{5}$ to salt-and-pepper changes to typical retinitis pigmentosa, ${ }^{\circ}$ and occasionally the changes may resemble choroideraemia.' Commonly the ophthalmoscopic picture may be quite polymorphic.' Rarely the fundus abnormalities may include macular colobomas ${ }^{\mathrm{x}}$ and optic disc oedema. ${ }^{+9} \mathrm{~A}$ less commonly known fundus presentation of Leber's congenital amaurosis is the appearance of multiple, irregular shaped, yellowish white flecks deep in the peripheral retina. The purpose of this paper is to emphasise this variant of the fundus appearance in this entity. Fluorescein angiography findings, which have not previously

Correspondence to E. Chew, MD, Hospital for Sick Children, Department of Ophthalmology, 555 University Avenuc, Toronto, Ontario M5G-1 X8. Canada. been described, are presented. The diagnostic ERG and the awareness of the polymorphism of the fundus appearances are emphasised.

\section{Case report}

The patient, a boy born in 1970 and enrolled in an institute for the partially sighted, was referred to the University of Nijmegen Ophthalmology Department because of unusual fundus lesions noted by his school ophthalmologist in 1978 . He was a product of a full-term pregnancy complicated by measles during the seventh month of gestation. The perinatal history was uneventful. He was noted to have nystagmus and an inability to follow objects at 3 months of age. ERG and EOG performed at another institute at age of 6 months were reported as unrecordable and flat, respectively. He displayed the digito-ocular sign. His milestone development was delayed with sitting up at 12 months and walking at 19 months. No neurological deficits were present. $\mathrm{He}$ is at present reported to have slight learning disability. His parents, who are third cousins, had normal eyes on examination. His only sib was also normal.

On examination in 1978 his visual acuity was poor light perception bilaterally. Searching nystagmus was present. He displayed enophthalmos, while slitlamp examination revealed entirely normal anterior segment. The pupils were $5 \mathrm{~mm}$ in diameter with a very slight, sluggish reaction to light. Ophthalmoscopy revealed optic discs of normal size and colour, with no evidence of disc oedema. Foveal reflexes were normal and the arterioles were attenuated. Yellowish white flecks, with well 


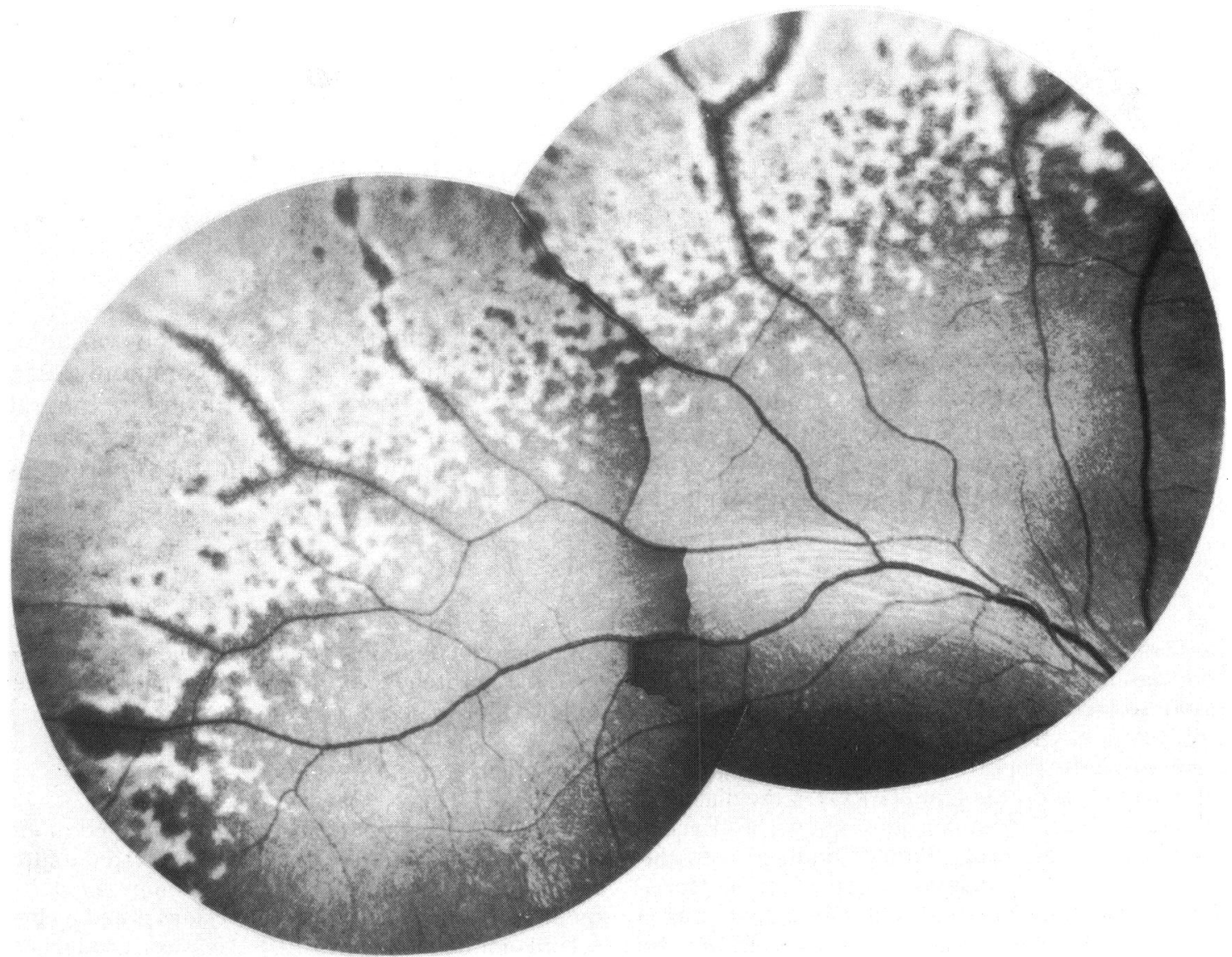

Fig. 1 Yellowish flecks in the mid periphery in a periarteriolar distribution seen on initial examination in 1978.

defined borders but becoming more confluent peripherally were found in a periarteriolar distribution in the midperiphery (Fig. 1). The nasal fundus as well as the posterior pole and the far periphery fundus adjacent to the ora serrata were spared. In this spared peripheral zone salt and pepper changes were seen. These lesions were remarkably symmetrical bilaterally.

In October 1982 a follow-up examination revealed essentially unchanged ocular status. These lesions, however, appeared more greyish in the peripheral aspects and the far peripheral pigmentation was more evident. The lesions appeared to have diminished in size in the peripheral margin (Figs. 2B, 3B) as compared with comparable areas seen in 1978 (Figs. 2A; 3A). A fluorescein angiogram showed hypofluorescence corresponding to the yellowish white flecks (Fig. 4). No staining or leakage of fluorescein resulted from these lesions, while hypofluorescence and window defects corresponded with hyper/hypopigmentation of the salt and pepper retinal changes. There was also leakage from the peripheral vessels over the areas of the flecks (Fig. 5).

\section{Discussion}

In addition to these unusual yellowish white flecks in the midperiphery of the fundus our patient presented with nystagmus, digito-oculo sign, congenital blindness, and an unrecordable ERG, confirming the diagnosis of Leber's congenital amaurosis. This striking fundus appearance is a rare picture seen in the syndrome complex of Leber's congenital amaurosis. It was first described by Franceschetti and Forni ${ }^{10}$ as 'marbilized fundus' with its unusual mosaic pattern and periarteriolar distribution of well-demarcated yellowish lesions located deep to the retinal vessels. Other authors reported on this unusual fundus variant of Leber's congenital amaurosis. ${ }^{11-16}$

The age of onset of these fundus lesions was 


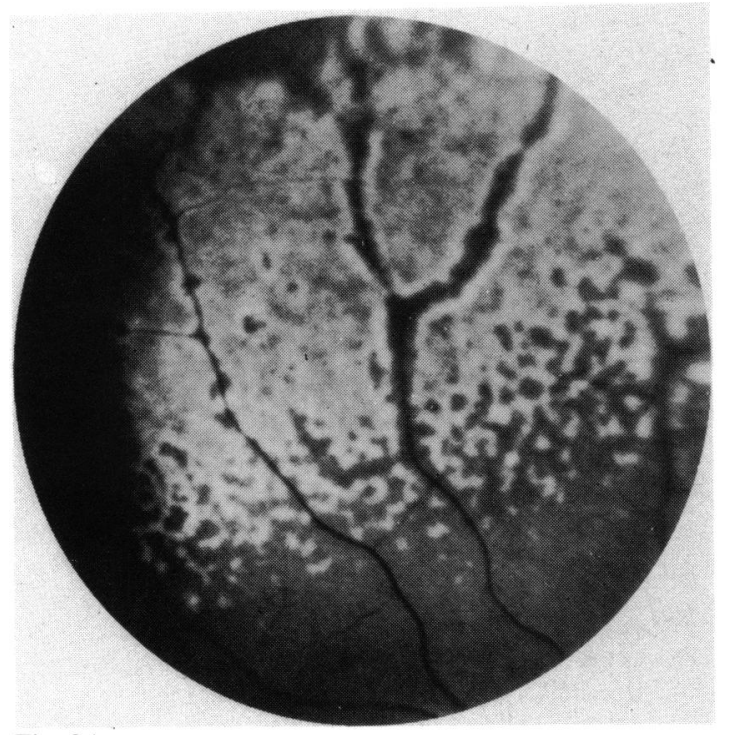

Fig. 2A

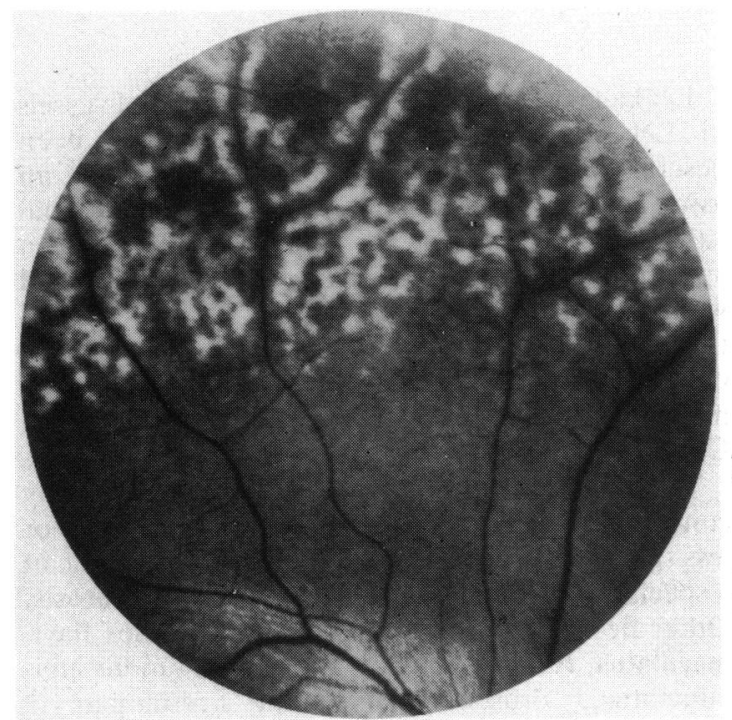

Fig. 2B

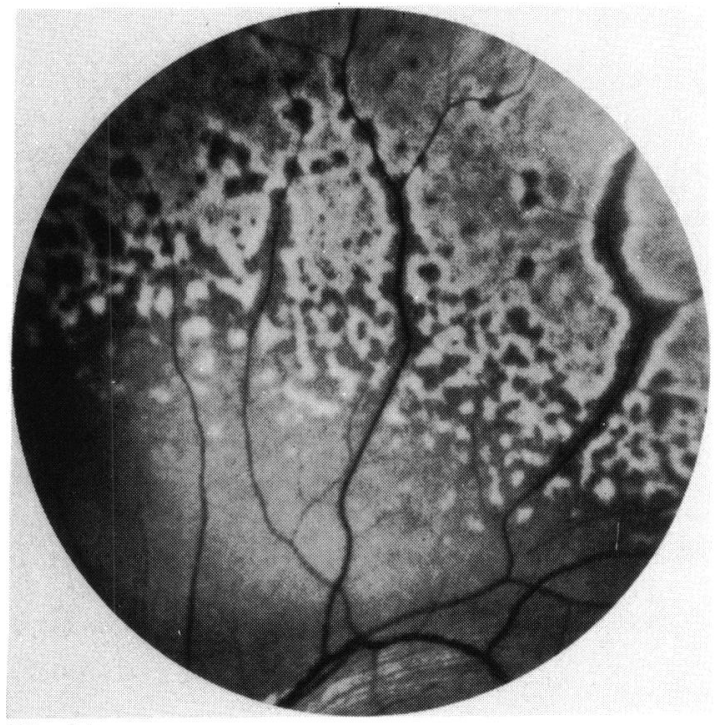

Fig. 3A

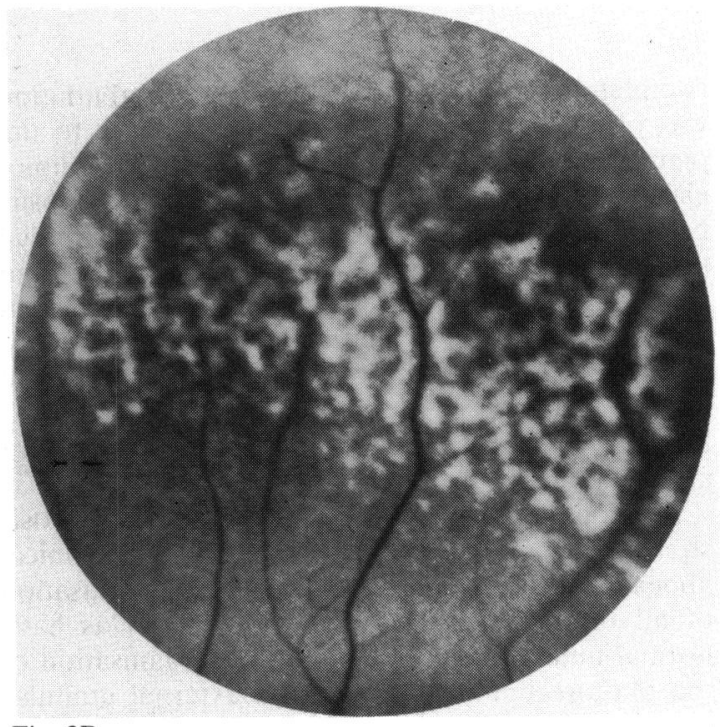

Fig. 3B

Figs. 2A and 3A The extensive distribution of these flecks are reduced in size and colour after four years of follow-up (Figs. $2 B$ and $3 B$ ).

unknown in our patient. Two patients described in the literature ${ }^{1214}$ were initially reported to have a normal appearing fundus and later found to have these lesions at the age of 21 months and 4 years when follow-up examinations were performed. It is unclear what these lesions, which appear to be deep to the retina, represent histologically. Mizuno et al. ${ }^{\text {14 }}$ reported on two patients, one whose fundus photo- graphs were not shown but had a clinical description which resembled the lesions found in our patient; the other patient had a different fundus affection of multiple white spots scattered throughout the entire fundus except for the macular area. Pathological study of the latter case revealed changes of the entire photoreceptor layer, with the outer segments of the cones either shortened and disorganised or 


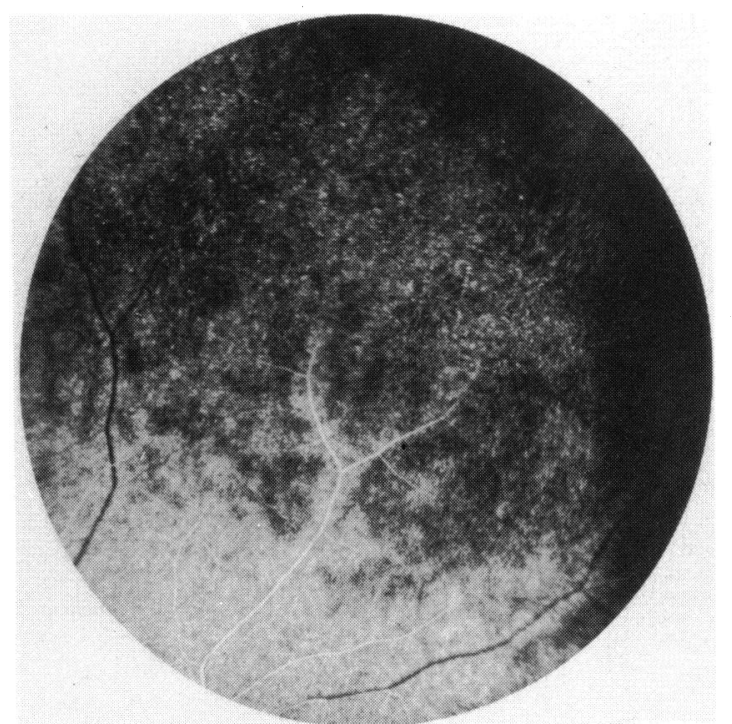

Fig. 4 Blockage of fluorescence by the yellowish white flecks.

completely absent. Lack of cellular differentiation was observed from the outer nuclear layer to the pigment epithelial layer. The most striking pathological feature was the presence of large deposits between the retina and the retinal pigment epithelial layer. They corresponded to the white spots and consisted of fragments of inner segments, apical processes of pigment epithelial cells, and macrophages. It is difficult to conclude that the same pathological lesions occurred in our patient, as Mizuno et al. ${ }^{14}$ described a different clinical picture in the fundus.

Previous reports of Leber's congenital amaurosis showed the pathology to be as variable as the clinical appearance of the fundus. Complete disorganisation of all retinal layers has been reported, ${ }^{17}$ as have normal inner retinal layers, with disorganisation of the photoreceptor cell layer and external granular layer. ${ }^{18}{ }^{19}$ Mizuno et al ${ }^{14}$ postulated that the pathological lesion represents a primary dystrophic disorder, as lack of cellular differentiation was prominent. A secondary degenerative process resulted in cellular debris and macrophages in the subretinal layer. This may be the case, as the degenerative process is seen as spots or flecks developing after birth.

Fluorescein angiography of these yellowish white lesions showed hypofluorescence without leakage or staining. Mizuno et al. ${ }^{1+}$ described a patient with a similar clinical appearance in the fundus, but fluorescein angiography showed fluorescence during the choroidal phase without leakage or staining.

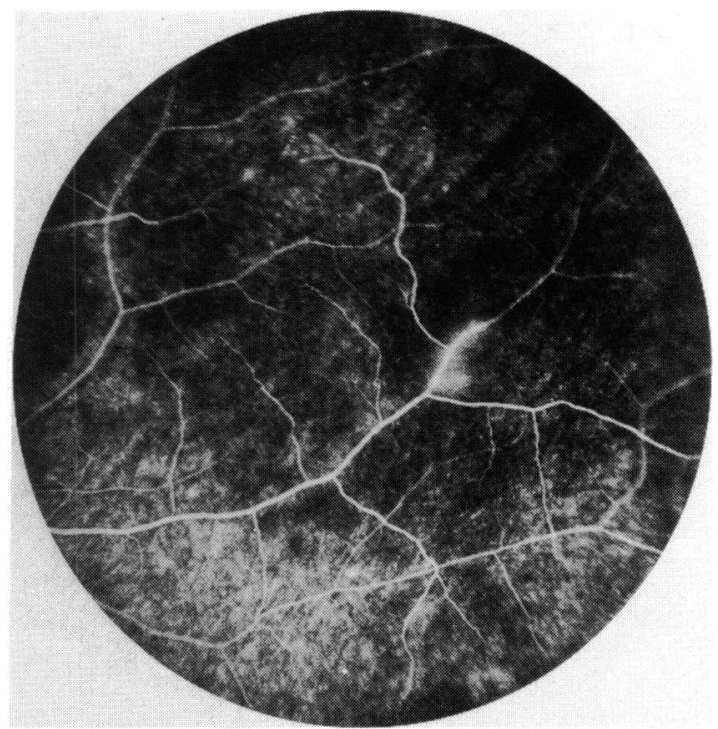

Fig. 5 Leakage of fluorescein from the peripheral vessels over the areas of the flecks.

Leakage of fluorescein from the peripheral vessels in Leber's congenital amaurosis has not been described before. It is not a surprising finding, as an association between retinal dystrophies and retinal vascular disease had been noted previously. ${ }^{211} \mathrm{An}$ appearance like Coats's disease has been associated with retinitis pigmentosa. ${ }^{21}$ Witschel ${ }^{22}$ has suggested that a toxic substance may be released by this degenerative process of the retina in retinitis pigmentosa, thus causing vascular leakage and a Coats's-disease-like picture.

The clinical presentation of such flecks may confuse the clinician. ${ }^{12}$ They appear to be more or less specific for this disease and may be diagnostic of a special subgroup of Leber's congenital amaurosis. Other flecked retina patterns such as fundus flavimaculatus, retinitis punctata albescens, fundus albipunctatus, drusen, ${ }^{23}$ crystalline retinopathy, ${ }^{24}$ vitamin A deficiency, ${ }^{2.5}$ and Kandori's flecked retina ${ }^{23}$ are generally easily distinguished from Leber's congenital amaurosis. A flecked pattern in a palisade distribution appears quite similar; however, the location is confined to the posterior pole. ${ }^{26}$ The larger, yellowish, fleck-like patterns such as are found in multiple vitelliform disease are clearly different. ${ }^{27}$

\section{References}

1 Leber T. Über Retinitis pigmentosa und angeborene Amaurosc. Arch Ophthalmol 1869; 15: 1-25.

2 Franceschetti A, Dicterle P. L'importance diagnostique de l'ERG dans les dégénérescences tapéto- rétiniennes avec 
rétrécissement du champ visucl et héméralopic. Confin Neurol 1954; 14: 184-6.

3 Pinckers AJL. Leber's congenital amaurosis as conceived by Leber. Ophthalmologica 1979; 179: 48-51.

4 Schappert-Kimmijser J, Henkes HE, van den Bosch J. Amaurosis congenita (Leber). Arch Ophthalmol 1959; 61: 211-8.

5 Winkelman JE, Horstein GPM. Congenital blindness in the presence of a normal fundus. Ophthalmologica 1959; 137: $423-5$.

6 François J. Leber's congenital tapetoretinal degeneration. Int Ophthalmol Clin 1968; 8: 931-47.

7 Franceschetti A, François J, Babel J. Chorioretinal heredodegenerations. Springficld: Thomas, 1974.

8 Margolis S, Scher, BM, Carr, RE. Macular colobomas in Leber's congenital amaurosis. Am J Ophthalmol 1977; 83: 27-31.

9 Flynn JT, Cullen RF. Disc ocdema in congenital amaurosis of Leber. Br J Ophthalmol 1975; 59: 497-502.

10 Franceschetti A, Forni S. Dégénérescence tapétorétinienne (type Leber) avec aspect marbre du fond de l'ocil périphérique. Ophthalmologica 1958; 135: 610-8.

11 Krill AE. Congenital anomalies of the eye. St Louis: Mosby, 1968.

12 Edwards WC, Price WD, Macdonald R. Congenital amaurosis of retinal origin (Leber). Am J Ophthalmol 1971; 72: 724-8.

13 Hirose T, Wand O. Amaurosis congenita (Leber). Ann Ophthalmol 1975; 7: 59-63.

14 Mizuno K. Takei Y, Scars ML, Peterson WS, Carr RE, Jampol LM. Leber's congenital amaurosis. Am J Ophthalmol 1977; 83: 32-42.

15 Noble KG, Carr RE. Leber's congenital amaurosis. A retro- spective study of 33 cases and a histopathological study of 1 casc. Arch Ophthalmol 1978; 96: 818-21.

16 Dekaban A, Carr R. Congenital amaurosis of retinal origin. Arch Neurol 1966; 44: 294-301.

17 Sorsby A, William CF. Retinal aplasia as a clinical entity. $\mathrm{Br}$ Med J 1960; i: 293-7.

18 François J, Hanssens M. Etude histo-pathologique de deux cas de dégéneréscence tapéto-rétinienne congénitale de Leber. Ann Oculist (Paris) 1969; 202: 127-55.

19 Kroll AJ, Kuwabara T. Electron microscopy of a retinal abiotrophy. Arch Ophthalmol 1964; 71: 683-90.

20 Grizzard WS, Deutman AF, Pinckers AJLG. Retinal dystrophies associated with peripheral retinal vasculopathy. $\mathrm{Br}$ J Ophthalmol 1978; 62: 188-94.

21 Notting JGA, Deutman AF. Leakage from retinal capillaries in hereditary dystrophies. In: DeLacy, JJ, ed. International Symposium on Fluorescein Angiography, Ghent, 1976. Doc Ophthalmol Proc 1976; 9: 439-47.

22 Witschel H. Retinopathia pigmentosa und Morbus Coats'. Klin Monatsbl Augenheilkd 1974; 164: 405-11.

23 Krill AE, Klein BA. Flecked retina syndrome. Arch Ophthalmol 1965; 74: 496-508.

24 Grizzard WS, Deutman AF, Nijhuis F, Aan de Kerk A. Crystalline retinopathy. Am J Ophthalmol 1978; 86: 81-8.

25 Bors F, Fells P. Reversal of the complications of self-induced vitamin A deficiency. Br J Ophthalmol 1971; 55: 210-4.

26 Krogh E, Recrsted, K. Flecked retina syndrome with palisade appearance of the periphery. Int Ophthalmol 1980; 2: 77-80.

27 Deutman AF. Retinal dystrophies with unusually large ycllowish flecks. In: Shimizu K, ed. International Congress No. 450, Kyoto, 1978. Concilium Ophthalmologicum XXIII:758. Amsterdam-Oxford: Excerpta Medica, 1978. 